\title{
Wnt3a mitigates acute lung injury by reducing P2X7 receptor-mediated alveolar epithelial type I cell death
}

\author{
Y Guo ${ }^{1}$, A Mishra', T Weng ${ }^{1}$, NR Chintagari ${ }^{1}$, Y Wang ${ }^{1}$, C Zhao ${ }^{1}$, C Huang ${ }^{1}$ and L Liu ${ }^{\star, 1}$
}

Acute lung injury (ALI) is characterized by pulmonary endothelial and epithelial cell damage, and loss of the alveolar-capillary barrier. We have previously shown that P2X7 receptor (P2X7R), a cell death receptor, is specifically expressed in alveolar epithelial type I cells (AEC I). In this study, we hypothesized that P2X7R-mediated purinergic signaling and its interaction with Wnt/ $\beta$-catenin signaling contributes to AEC I death. We examined the effect of P2X7R agonist 2'-3'-0-(4-benzoylbenzoyl)-ATP (BzATP) and Wnt agonist Wnt3a on AEC I death in vitro and in vivo. We also assessed the therapeutic potential of Wnt3a in a clinically relevant ALI model of intratracheal lipopolysaccharide (LPS) exposure in ventilated mice. We found that the activation of P2X7R by BzATP caused the death of AEC I by suppressing Wnt/ $\beta$-catenin signaling through stimulating glycogen synthase kinase-3 $\beta($ GSK-3 $\beta$ ) and proteasome. On the other hand, the activation of Wnt/ $\beta$-catenin signaling by Wnt3a, GSK-3 $\beta$ inhibitor, or proteasome inhibitor blocked the P2X7R-mediated cell death. More importantly, Wnt3a attenuated the AEC I damage caused by intratracheal instillation of BzATP in rats or LPS in ventilated mice. Our results suggest that Wnt3a overrides the effect of P2X7R on the Wnt/ $\beta$-catenin signaling to prevent the AEC I death and restrict the severity of ALI.

Cell Death and Disease (2014) 5, e1286; doi:10.1038/cddis.2014.254; published online 12 June 2014

Acute lung injury (ALI) and its severe form, acute respiratory distress syndrome (ARDS), are life-threatening diseases caused by a variety of reasons, including sepsis, trauma, and pneumonia. ${ }^{1}$ The alveolar epithelium consists of alveolar epithelial type I cells (AEC I) and alveolar epithelial type II cells (AEC II) and is believed to have an important role in the pathogenesis of ALI. AEC I cover most of the alveolar surface area and are the primary barrier of defense against the variety of insults. ${ }^{2,3}$ They are more sensitive to injury in comparison with other lung cells. Damage of AEC I is observed in all kinds of $\mathrm{ALI}$, leading to the deficiency of gas exchange and disruption of fluid clearance. The molecular mechanisms of AEC I death during ALI have been studied to some extent including the regulation of several signaling pathways, such as TGF- $\beta$ pathway, $\mathrm{NF} \kappa \mathrm{B}$ pathway, and Fas/FasL-mediated pathway. ${ }^{4}$

Wnt is a family of secreted glycoprotein and has an important role in development, tissue regeneration, and cell fate determination. ${ }^{5}$ In the absence of Wnt ligands, the intracellular $\beta$-catenin is phosphorylated by glycogen synthase kinase-3 $\beta$ (GSK-3 $\beta$ ) and degraded in proteasomes. The binding of Wnt ligands with frizzled receptors leads to the disruption of GSK-3 $\beta$-mediated phosphorylation of $\beta$-catenin and thus attenuation of proteasome-mediated degradation. The stabilized $\beta$-catenin then translocates into the nucleus, where it binds to T-cell factor (TCF)/lymphoid enhancer factor (LEF) transcription factors to increase the transcription of its downstream genes. We have previously shown that pleiotrophin and miR-375 regulate $\mathrm{Wnt} / \beta$-catenin signaling during alveolar epithelial cell differentiation. ${ }^{6,7}$ Recent studies reveal essential roles of $\mathrm{Wnt} / \beta$-catenin signaling in the pathogenesis of several lung diseases, including pulmonary fibrosis, ${ }^{8,9}$ asthma, ${ }^{10}$ and chronic obstructive pulmonary disease (COPD). ${ }^{11,12}$ Activation of $\mathrm{Wnt} / \beta$-catenin signaling promotes AEC II survival, ${ }^{13}$ whereas deletion of $\beta$-catenin in AEC results in an increased AEC death in bleomycin-induced lung injury model. ${ }^{8}$ Transepithelial migration of neutrophils also activates Wnt/ $\beta$-catenin signaling in AEC II and accelerates the epithelial repair. ${ }^{14}$ Thus, it is important to explore the potential contribution of $\mathrm{Wnt} / \beta$-catenin to AEC I damage during ALI.

$\mathrm{P} 2 \mathrm{X} 7$ receptor $(\mathrm{P} 2 \mathrm{X} 7 \mathrm{R})$ is a transmembrane ligand-gated ion channel receptor activated by extracellular ATP. ${ }^{15} \mathrm{We}$ have previously found that P2X7R is specifically expressed in AEC I and regulates lung surfactant secretion. ${ }^{16,17}$ However, high concentrations of ATP or sustained stimulations could

\footnotetext{
${ }^{1}$ Department of Physiological Sciences, Center for Veterinary Health Sciences, Lundberg-Kienlen Lung Biology and Toxicology Laboratorym, Oklahoma State University, Stillwater, OK 74078, USA

${ }^{*}$ Corresponding author: L Liu, Department of Physiological Sciences, Center for Veterinary Health Sciences, Lundberg-Kienlen Lung Biology and Toxicology Laboratorym, Oklahoma State University, 264 McElroy Hall, Stillwater, OK 74078, USA. Tel: + 1405744 4526; Fax: + 1405744 8263; E-mail: lin.liu@ okstate.edu Abbreviations: $\mathrm{ABC}$, activated $\beta$-catenin; AEC, alveolar epithelial cells; AEC I, type I alveolar epithelial cells; AEC II, type II alveolar epithelial cells; ALI, acute lung injury; AMC, 7-amido-4-methylcoumarin; ARDS, acute respiratory distress syndrome; ATP, adenosine triphosphate; BAL, bronchoalveolar lavage; Bcl-2, B-cell lymphoma 2; Bmp4, bone morphogenetic protein 4; BzATP, 2'(3')-O-(4-Benzoylbenzoyl)adenosine-5'-triphosphate; CCND1, cyclin D1; CCNE1, cyclin E1; Con_CM, control conditional medium; COPD, chronic obstructive pulmonary disease; DAPI, 4',6-diamidino-2-phenylindole; DMEM, Dulbecco's modified Eagle's medium; FBS, fetal bovine serum; GSK-3 $\beta$, glycogen synthase kinase-3 $\beta$; HEK293, human embryonic kidney 293 cells; IgG, immunoglobulin G; LDH, lactate dehydrogenase; LEF, lymphoid enhancer factor; LPS, lipopolysaccharide; M-MLV, Moloney murine leukemia virus; mRNA, messenger RNA; MV, mechanical ventilation; NFAT, nuclear factor of activated T cells; $\mathrm{NF} \kappa \mathrm{B}$, nuclear factor kappa-light-chain-enhancer of activated B cells; P2X7R, P2X purinoceptor 7; PAGE, polyacrylamide gel electrophoresis; PBS, phosphate-buffered saline; PCNA, proliferating cell nuclear antigen; PEEP, positive end-expiratory pressure; SDS, sodium dodecyl sulfate; Ser, serine; T1 $\alpha$, podoplanin; TBS, Tris-buffered saline; TCF, T-cell factor; TGF- $\beta$, transforming growth factor beta; TNF- $\alpha$, tumor necrosis factor alpha; TRAIL, TNF-related apoptosisinducing ligand; Tyr, tyrosine; Wnt3a_CM, Wnt3a conditional medium; Wnt5a_CM, Wnt5a conditional medium

Received 07.1.14; revised 05.4.14; accepted 14.4.14; Edited by M Agostini
} 
lead to apoptosis or necrosis in P2X7R-expressing cells. ${ }^{18,19}$ P2X7R knockout mice have shown a protective phenotype in lipopolysaccharide (LPS)-induced ALI. ${ }^{20}$ Together with its ability to modulate pulmonary inflammatory response, ${ }^{21}$ P2X7R could act as a potential regulator of AEC I cell death in response to pathological insults.

In this study, we reported for the first time the important integration of $\mathrm{Wnt} / \beta$-catenin signaling and P2X7R-mediated purinergic signaling in AEC I death during ALI. The finding could be translated into a new therapeutic approach.

\section{Results}

P2X7R expression in lung cells. We have previously shown that P2X7R is specifically expressed in AEC I of the lung. ${ }^{16}$ Here we examined the expression of P2X7R in several lung cell lines using western blot analysis. HEK293P2X7R cells, stably transfected cell line with P2X7R, were used as a positive control. P2X7R expression was observed in E10, an AEC I cell line and MLE15, a lung epithelial cell line. However, HEK293 (a human epithelial kidney cell line), R3/1 (a rat AEC I cell line), A549 (a human carcinoma AEC II cell line), Pre-TII (a rat fetal AEC II cell line), H441 (a human lung papillary adenocarcinoma epithelial cell line), RLE-6TN (a rat lung AEC II cell line), and RFL-6 (a fetal lung fibroblast cell line) had no P2X7R expression (Supplementary Figure $\mathrm{S} 1 \mathrm{a}$ in the online data supplement). The mRNA expression of mouse P2X subunits was further analyzed using PCR. P2X3R, P2X4R, P2X6R, and P2X7R subunits were highly expressed in E10 cells. The expression levels of P2X1R and P2X5R subunits were barely detectable, and P2X2R had no expression in E10 cells. All of the P2X subunits were expressed in the lung tissue (Supplementary Figure S1b).

Prolonged activation of P2X7R causes cell death. As $\mathrm{P} 2 \mathrm{X} 7 \mathrm{R}$ is well known as a cell death receptor, we tested cell viability upon the activation of P2X7R in E10 cells. Treatment of E10 cells with 2'-3'-O-(4-benzoylbenzoyl)-ATP (BzATP), a potent P2X7R agonist, for $12 \mathrm{~h}$ significantly decreased cell viability in a dose-dependent manner as measured with MTT assay and counting cell numbers (Figure 1a and Supplementary Figure S2a). Direct cell lysis was monitored by lactate dehydrogenase (LDH) release. High doses $(>200 \mu \mathrm{M})$ of BzATP dramatically increased LDH release from dead cells (Figure 1b). To determine the specificity of BzATP, oxidized ATP (oATP, a P2X7R antagonist) was utilized to block P2X7R activity. Pre-incubation of E10 cells with $500 \mu \mathrm{M}$ oATP totally attenuated the BzATP effect on cell viability (Figure 1c) and LDH release (Supplementary Figure $\mathrm{S} 2 \mathrm{~b})$. We have previously shown that adenovirus-based shRNAs significantly reduce $\mathrm{P} 2 \mathrm{XR}$ protein levels in $\mathrm{E} 10$ cells. ${ }^{17}$ The knockdown of P2X7R under the same conditions also inhibited the BzATP-induced reduction in cell viability (Figure 1d) and increase in LDH release (Supplementary Figure S3a). In addition, BzATP did not induce cell death in the lung cells, A549 and H441, that do not express P2X7R (Supplementary Figure S3c and d). To determine whether BzATP-mediated cell death is reversible, E10 cells were
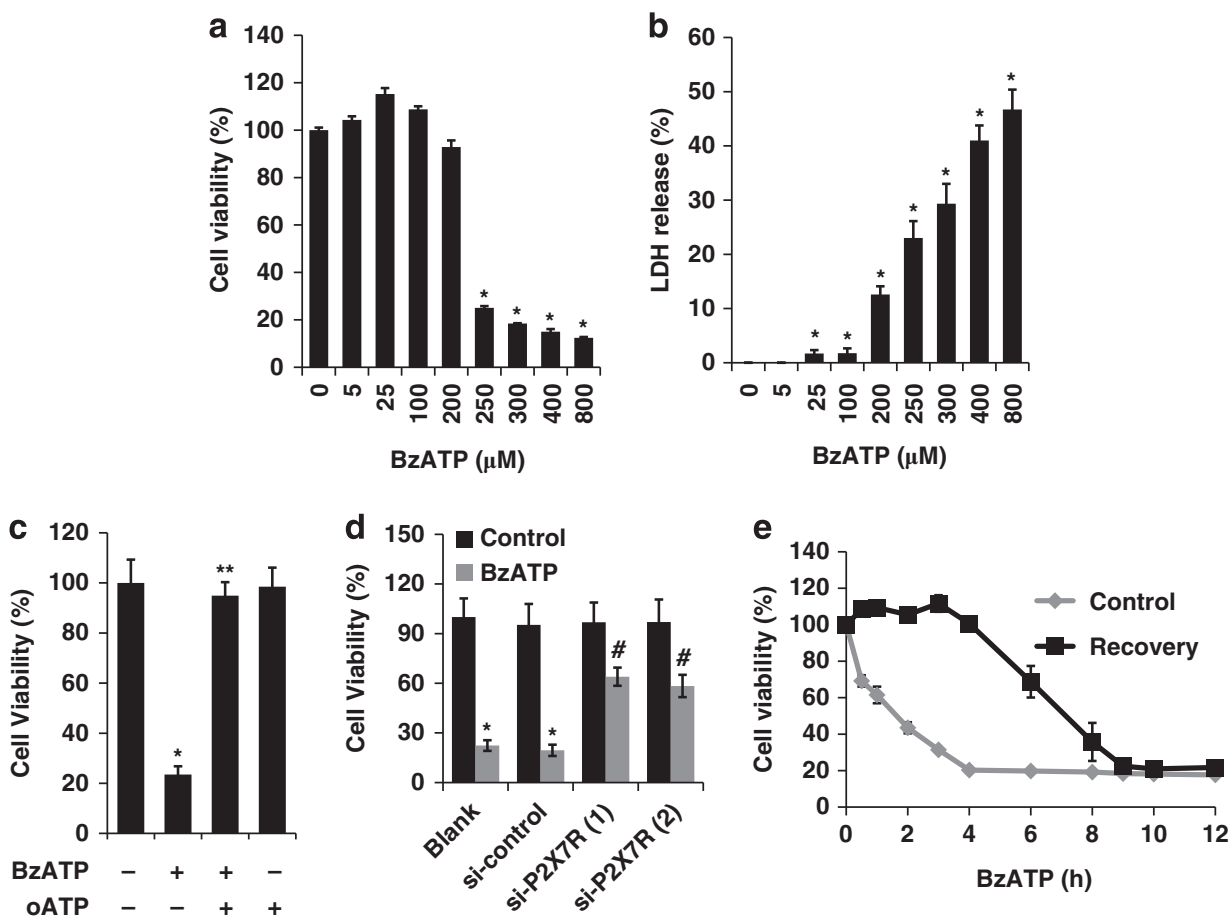

Figure 1 Prolonged activation of P2X7R leads to E10 cell death. (a and $\mathbf{b}) \mathrm{E} 10$ cells were incubated with different concentrations of BzATP for $12 \mathrm{~h}$. Cell viability and LDH release were measured. (c) E10 cells were treated with $400 \mu \mathrm{M}$ BzATP in the absence or presence of $500 \mu \mathrm{M}$ oATP for $12 \mathrm{~h}$, and cell viability was measured. (d) E10 cells were transduced with adenovirus-based shRNA vectors (virus control (si-control), si-P2X7R ${ }^{1}$ and si-P2X7R ${ }^{2}$ ) for 4 days and then treated with $400 \mu \mathrm{M} \mathrm{BzATP}$ for $12 \mathrm{~h}$. Cell viability was measured. (e) E10 cells were treated with $400 \mu \mathrm{M}$ BzATP for different times and recovered in a normal medium without BzATP for $8 \mathrm{~h}$; cell viability was determined. Data shown are means \pm S.E.M. of three independent experiments, and statistical significance was determined by one-way ANOVA analysis with post hoc Tukey's test. ${ }^{*} P<0.001$ versus control without any treatment or 0 time, ${ }^{* \star} P<0.001$ versus $400 \mu \mathrm{M}$ BzATP, and ${ }^{\sharp} P<0.005$ versus si-control 
treated with BzATP for various times and were allowed to recover in a normal medium without BzATP for $8 \mathrm{~h}$. The cells treated for up to $6 \mathrm{~h}$ were reversible. However, if the cells were treated for longer than $8 \mathrm{~h}$, the cells cannot be recovered (Figure 1e).

Activation of P2X7R suppresses Wnt/ $\beta$-catenin signaling. $\mathrm{Wnt} / \beta$-catenin signaling is important for cell proliferation and survival. ${ }^{5}$ We determined whether P2X7R-mediated cell death is due to downregulation of the $\mathrm{Wnt} / \beta$-catenin signaling. Several components of $\mathrm{Wnt} / \beta$-catenin signaling were analyzed after BzATP treatment. Western blot analysis demonstrated that activated $\beta$-catenin and, to a lesser extent, total $\beta$-catenin were downregulated by BzATP treatment (Figure 2a). Proliferating cell nuclear antigen (PCNA) and B-cell lymphoma 2 (Bcl-2), classic cell survival proteins were reduced as well (Figure 2a). To further determine the effect of BzATP on $\beta$-catenin/TCF/LEF activity, dual-luciferase assay was used to determine the activities of TOPflash, a TCF/LEF reporter plasmid expressing firefly luciferase. BzATP significantly decreased TOPflash activity. However, BzATP had no effect on the activity of FOPflash, a plasmid containing a mutated TCF/LEF-binding site (Figure 2b). Furthermore, we examined the mRNA expression of several

a

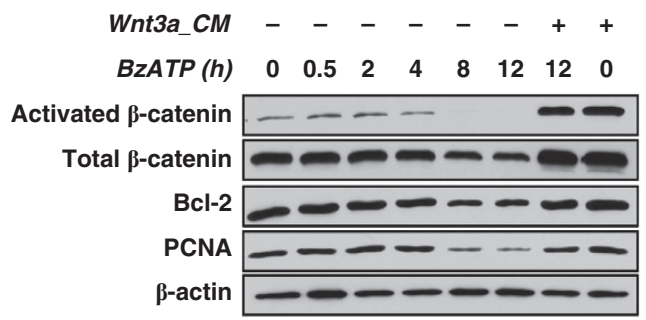

b

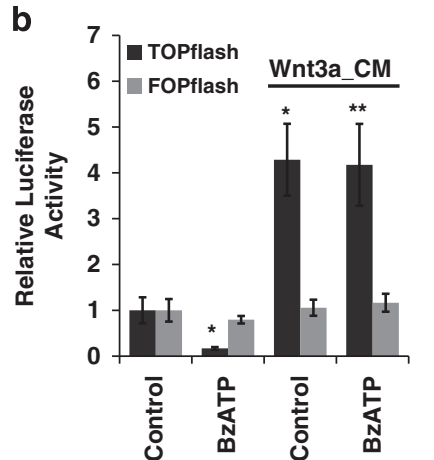

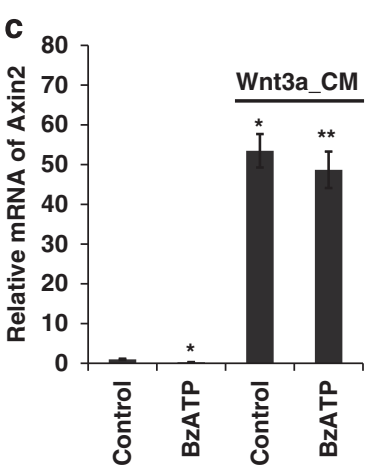

Figure 2 Activation of $\mathrm{P} 2 \mathrm{X} 7 \mathrm{R}$ represses Wnt $/ \beta$-catenin signaling. (a) E10 cells were treated with $400 \mu \mathrm{M}$ BzATP for $0,0.5,2,4,8$, and $12 \mathrm{~h}$ with or without $50 \%$ Wnt3a_CM. Western blot analysis was carried out to determine the protein expression of activated $\beta$-catenin, total $\beta$-catenin, Bcl-2, and PCNA. The expression of $\beta$-actin was used as an internal control. (b) Two hundred nanograms TOPflash/ FOPflash and $1 \mathrm{ng}$ pRL-TK, a control plasmid expressing a Renilla luciferase, were transfected into $\mathrm{E} 10$ cells. Two days after transfection, E10 cells were treated with $400 \mu \mathrm{M}$ BzATP for $4 \mathrm{~h}$ with or without $50 \%$ Wnt3a_CM. Dual-luciferase assay was performed and the results were expressed as the ratio of TOPflash/FOPflash luciferase activity to pRL-TK. (c) E10 cells were stimulated with $400 \mu \mathrm{M}$ BzATP for $8 \mathrm{~h}$ with or without $50 \%$ Wnt3a_CM. The relative mRNA expression of Axin2 was determined using real-time PCR and normalized to 18S rRNA. Data shown are means \pm S.E.M. of three independent experiments. Statistical significance was determined by ANOVA analysis with post hoc Tukey's test. ${ }^{*} P<0.001$ versus control. ${ }^{*} P<0.001$ versus BzATP without Wnt3a_CM
Wnt/ $\beta$-catenin downstream genes: Bmp4, Axin2, Cyclin D1, and Cyclin E1. Real-time PCR showed that the expression of all these four target genes was inhibited (Figure $2 \mathrm{c}$ and Supplementary Figure S4). Our results indicate that $\mathrm{Wnt} / \beta$ catenin signaling is suppressed by BzATP treatment.

Wnt3a blocks P2X7R-mediated cell death. To evaluate the role of $\mathrm{Wnt} / \beta$-catenin signaling in P2X7R-mediated cell death, we activated $\mathrm{Wnt} / \beta$-catenin signaling with its natural ligand, Wnt3a, and examined its effect on P2X7R-mediated depression of $\mathrm{Wnt} / \beta$-catenin signaling and cell death. Wnt3a_CM and Wnt5a_CM were obtained from L-cells that stably expressed Wnt3a or Wnt5a. The medium from L-cells (Con_CM) was used as a control. The pre-treatment of E10 cells with Wnt3a_CM prevented BzATP-mediated downregulation of total $\beta$-catenin and activated $\beta$-catenin (Figure 2a), inhibition of TOPflash activity (Figure $2 \mathrm{~b}$ ) and decrease in Axin2 (Figure 2c). As shown above, BzATP treatment caused a decrease in cell number of E10 cells. Wnt3a_CM, but not Wnt5a_CM or Con_CM, prevented the BzATP-induced decrease in cell number (Figure 3a). Immunostaining confirmed the activation of $\mathrm{Wnt} / \beta$-catenin in $\mathrm{E} 10$ cells by Wnt3a as evidenced by nuclear translocation of $\beta$-catenin (Figure 3a). Activation of $\mathrm{Wnt} / \beta$-catenin signaling by Wnt3a_CM in E10 cells also blocked P2X7-mediated decrease in cell viability and increase in $\mathrm{LDH}$ release (Figures $3 \mathrm{~b}$ and $\mathrm{c}$ ). Wnt3a_CM also protected primary AEC-I-like cells from BzATP-induced cell death (Figure 3d). YO-PRO dye uptake triggered by BzATP was not inhibited by Wnt3a_CM (Supplementary Figure S5), indicating that P2X7R activity itself is not affected by the activation of $\mathrm{Wnt} / \beta$-catenin signaling.

Activation of P2X7R stimulates GSK-3 $\beta$ and proteasome activities. As Wnt3a is known to inhibit GSK-3 $\beta$, resulting in the activation of $\mathrm{Wnt} / \beta$-catenin signaling, ${ }^{5}$ we examined whether the downregulation of the $\mathrm{Wnt} / \beta$-catenin pathway by $\mathrm{P} 2 \mathrm{X} 7 \mathrm{R}$ is through the stimulation of GSK-3 $\beta$. We monitored the phosphorylation of $\mathrm{Y} 216$, an activated form of GSK-3 $\beta$, and the phosphorylation of S9, an inactivated form of GSK-3 $\beta$. The activation of P2X7R by BzATP increased the phosphorylation of $\mathrm{Y} 216$ and decreased the phosphorylation of S9 in GSK-3 $\beta$ without affecting the total GSK-3 $\beta$ expression (Figure 4a). The result indicates that BzATP stimulates GSK-3 $\beta$ activity. As expected, $\mathrm{LiCl}$, a selective inhibitor of GSK-3 $\beta$, activated $\mathrm{Wnt} / \beta$-catenin signaling as indicated by the translocation of $\beta$-catenin into the nucleus (Supplementary Figure S6) and reduced BzATP-mediated cell death (Figures $4 b$ and $c$ ).

As phosphorylated $\beta$-catenin by GSK-3 $\beta$ can be degraded through the ubiquitin-proteasome system, ${ }^{5}$ we determined whether BzATP affected proteasome activity. The treatment of E10 cells with BzATP increased proteasome activity by onefold (Figure 5a). Furthermore, MG-132, a proteasome inhibitor, blocked BzATP-mediated reduction of cell viability and increase in $\mathrm{LDH}$ release (Figures $5 \mathrm{~b}$ and $\mathrm{c}$ ).

Wnt3a reduces AEC I death in BzATP-induced $A L I$ in rats. To further investigate the role of $P 2 X 7 R$ in $A E C I$ death, BzATP was intratracheally instilled into the lung of rats. 

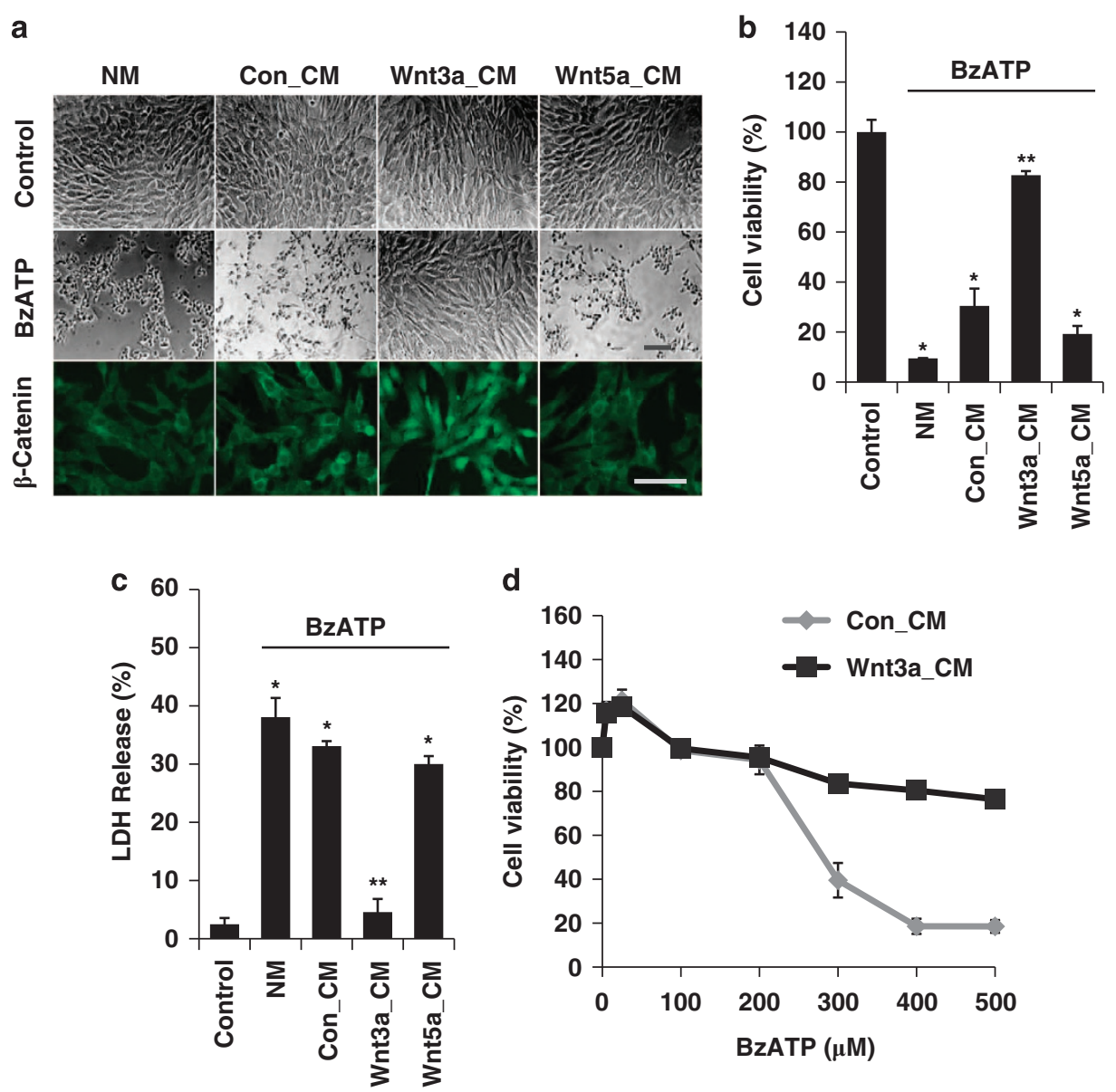

Figure 3 Wnt3a blocks P2X7R-mediated cell death. E10 cells were treated with $400 \mu \mathrm{M}$ BzATP for $8 \mathrm{~h}$ together with $50 \%$ Control (Con), Wnt3a, or Wnt5a CM. (a) Immunostaining was carried out to determine $\beta$-catenin localization (Scale bar: $50 \mu \mathrm{m}$ ). (b and c) Cell viability and LDH release were measured. Data shown are means \pm S.E.M. Statistical significance was determined by ANOVA analysis with post hoc Tukey's test. ${ }^{*} P<0.001$ versus control. ${ }^{*} P<0.001$ versus Con_CM. $n=3$. (d) Primary AEC-I-like cells were treated with 0-400 $\mu \mathrm{M}$ BzATP for $12 \mathrm{~h}$ with $50 \%$ Control (Con) or Wnt3a_CM, and Cell viability was measured

Histological examination of lung tissues showed evidence of diffused lung injury with significant alveolar septal necrosis and edema formation seen in BzATP-treated mice (Figure 6A). Bronchoalveolar lavage (BAL) cell analysis indicated that activation of P2X7R led to a 3.2-fold increase in alveolar macrophages. However, no significant neutrophil infiltrations were observed (Figure 6B). BAL protein level was elevated by BzATP (Supplementary Figure S7). LDH activity in BAL, representing necrotic cell death, was also increased by BzATP treatment (Figure $6 \mathrm{C}$ ). An increase in $\mathrm{T} 1 \alpha$, an AEC I marker, was observed in BAL of the BzATP-treated group, indicating AEC I damage (Figure 6D). Instillation of Wnt3a_CM together with BzATP dramatically reduced the number of alveolar macrophages in BAL and BAL protein concentration in comparison with Con_CM (Figure 6B and Supplementary Figure S7). Wnt3a also significantly decreased $\mathrm{LDH}$ and $\mathrm{T} 1 \alpha$ release caused by BzATP (Figures $6 \mathrm{C}$ and $\mathrm{D}$ ). It was noted that both protein concentration and LDH activity in BAL were higher in Con_CM than in the PBS group. This is likely because of the existence of proteins and LDH in the conditioned medium (CM). These results indicated that Wnt3a can limit AEC I death induced by activation of P2X7R in rats.
Wnt3a reduces AEC I death during LPS-induced $A L I$ in a ventilated mouse model. As bacterial infection and mechanical ventilation (MV) are two major causes of ALI/ARDS in clinical situations, we further took use of a two-hit mouse model of $\mathrm{ALI}^{22}$ which account for the influences of both factors: LPS as bacterial infection and noninjurious MV as clinical MV support. In comparison with the Con_CM group, Wnt3a_CM dramatically reduced the protein concentration in BAL fluid (Figure 7a). LDH activity in BAL was also decreased $40 \%$ in the Wnt3a_CM-treated group (Figure $7 \mathrm{~b}$ ). Most importantly, T1 $\alpha$ in BAL was $70 \%$ less in Wnt3a_CM-treated group than the control group (Figure 7c). These results indicated that the activation of canonical $\mathrm{Wnt} / \beta$-catenin signaling can significantly reduce AEC I death during ALI.

\section{Discussion}

In this study, we investigated the mechanisms of P2X7R-mediated AEC I death during ALI. We found that the activation of P2X7R caused AEC I death at least partly by depressing the $\mathrm{Wnt} / \beta$-catenin signaling pathway via GSK-3 $\beta$ and proteasome. The activation of the $\mathrm{Wnt} / \beta$-catenin 
signaling or inhibition of GSK-3 $\beta$ or proteasome prevented P2X7R-mediated AEC I death. Furthermore, Wnt3a significantly reduced the AEC I damage caused by intratracheal instillation of BzATP in rats and LPS exposure in a ventilated mouse model.

ATP-induced cell death has been observed in P2X7Rexpressing cells and can be blocked by P2X7R inhibitors. ${ }^{18,19}$ We have previously shown that P2X7R is highly expressed in AEC I in the lung. ${ }^{16}$ This gives us an idea that P2X7R might mediate AEC I death. This is supported by our current data
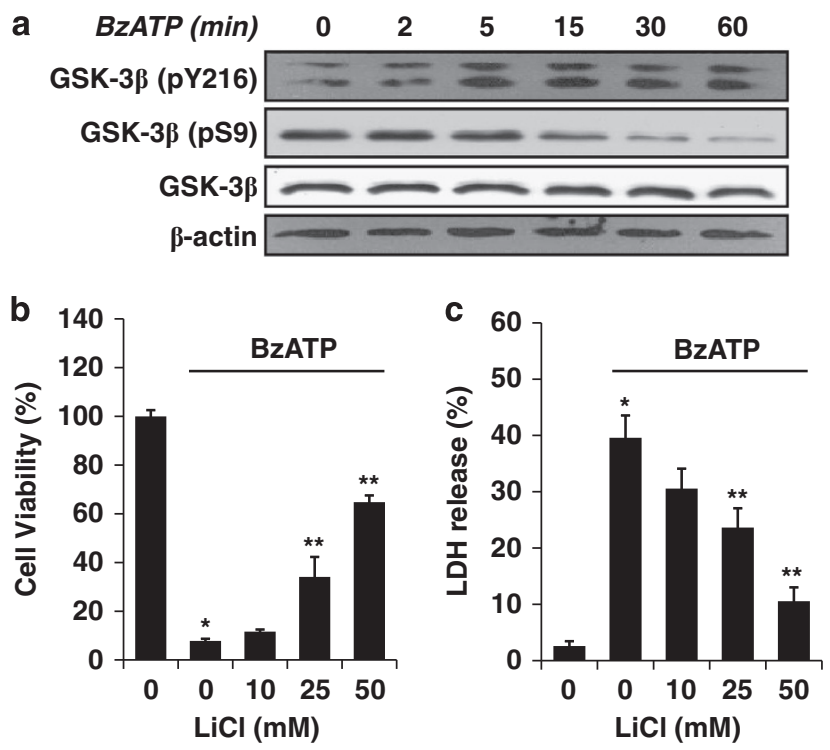

Figure 4 Activation of P2X7R stimulates GSK-3 $\beta$. (a) E10 cells were incubated with $400 \mu \mathrm{M}$ BzATP for different periods of time. The level of Tyr-216 (pY216) and Ser-9 (pS9) phosphorylated GSK-3 $\beta$ and total GSK-3 $\beta$ were determined using western blot analysis. (b and c) E10 cells were treated with $400 \mu \mathrm{M}$ BzATP together with different concentrations of $\mathrm{LiCl}$ for $8 \mathrm{~h}$. Cell viability and released LDH were measured. Data shown are means \pm S.E.M. of three independent experiments. Statistical significance was determined with ANOVA analysis with post hoc Tukey's test. ${ }^{*} P<0.01$ versus control (no BzATP). ${ }^{* \star} P<0.01$ versus BzATP only showing that the treatment of E10 with BzATP, a specific P2X7R agonist, decreased cell viability in a dose-dependent manner, which was blocked by oATP, a P2X7R antagonist.

Activating $W n t / \beta$-catenin signaling inhibits apoptosis induced by activating the intrinsic or mitochondrial pathway, such as starvation or hydrogen peroxide ${ }^{23}$ or the extracellular or receptor pathway, such as TRAIL and TNF- $\alpha .{ }^{23}$ Blocking the $\mathrm{Wnt} / \beta$-catenin pathway prevents cell proliferation and results in apoptosis or necrosis. ${ }^{24}$ BzATP-induced AEC I death is likely through downregulating the $\mathrm{Wnt} / \beta$-catenin signaling pathway since we observed BzATP activated GSK-3 $\beta$ and proteasome activity and decreased $\beta$-catenin protein level.

The high level of extracellular ATP released under pathological conditions could be one of the major factors in the pathogenesis of ALI. ${ }^{25}$ Extracellular ATP-induced cell death has been observed in inflammatory diseases, including colitis, ${ }^{26}$ spinal cord injury, ${ }^{27}$ and glomerulonephritis. ${ }^{28}$ It is likely that in ALI, a high level of extracellular ATP acts on P2X7R and induces cell death by apoptosis and/or necrosis. P2X7R-deficient mice have a protective phenotype in LPSinduced $\mathrm{ALI}^{20}$ and bleomycin-induced lung fibrosis ${ }^{25}$ in terms of attenuated inflammation. P2X7R is also involved in the pathogenesis of several chronic lung inflammatory diseases such as asthma and emphysema, in which it functions as an inflammatory mediator. ${ }^{29}$ In our study, direct activation of P2X7R through intratracheal instillation of BzATP caused severe $A E C$ I death and $\mathrm{LDH}$ release into the alveolar space, supporting the contribution of P2X7R to the pathogenesis of ALI.

There are no standard methods for activating Wnt/ $\beta$-catenin signaling in the lung, an organ with more than 40 different types of cells. Wnt3a is one of the reported ligands constitutively present in the lung that can activate $\mathrm{Wnt} / \beta$ catenin signaling in alveolar epithelium. ${ }^{9}$ We demonstrated that the activation of $\mathrm{Wnt} / \beta$-catenin in the lungs by $\mathrm{Wnt} 3 \mathrm{a}$ reduced AEC I damage in two rodent models: BzATP-induced $\mathrm{ALI}$ in rat and a clinically relevant LPS and MV model in mice. GSK3 $\beta$ inhibitors are other compounds that are used to
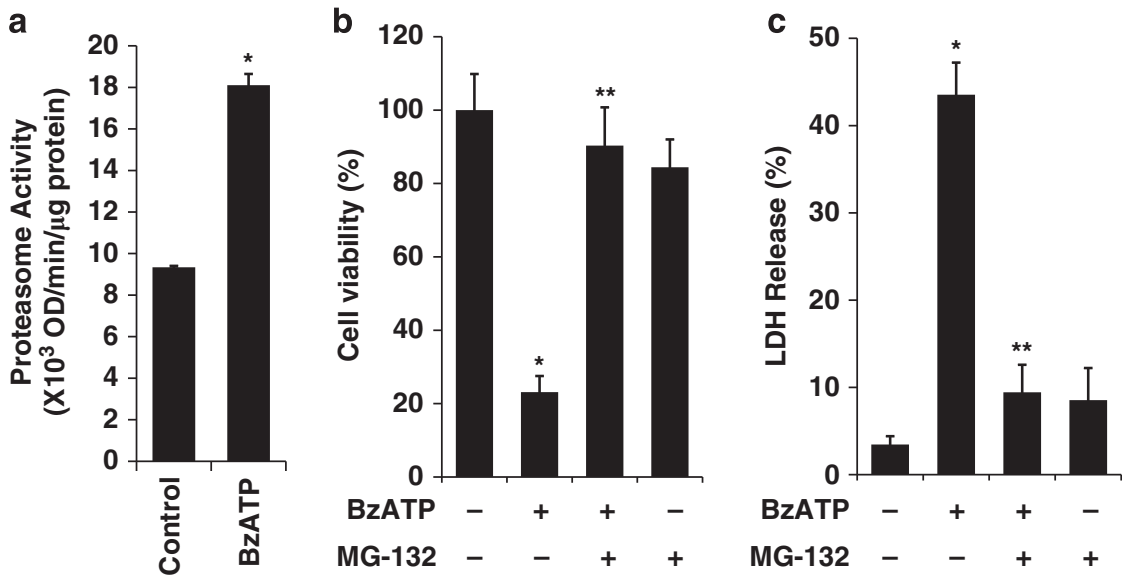

Figure 5 Proteasome is involved in P2X7R-mediated cell death. (a) E10 cells were treated with $400 \mu \mathrm{M}$ BzATP for $6 \mathrm{~h}$. Cell lysate was incubated with Suc-LLVY-AMC. Fluorescence was measured every $5 \mathrm{~min}$ for $30 \mathrm{~min}$. The amount of AMC liberated per unit time was calculated as relative proteasome activity. (b and c) E10 cells were treated with $400 \mu \mathrm{M}$ BzATP with or without $500 \mu \mathrm{M}$ MG-132 for $8 \mathrm{~h}$. Cell viability and released LDH were measured. Values represent means \pm S.E.M. of three independent experiments. Statistical significance was determined with ANOVA analysis with post hoc Tukey's test. ${ }^{*} P<0.001$ versus Control. ${ }^{* *} P<0.001$ versus BzATP alone 

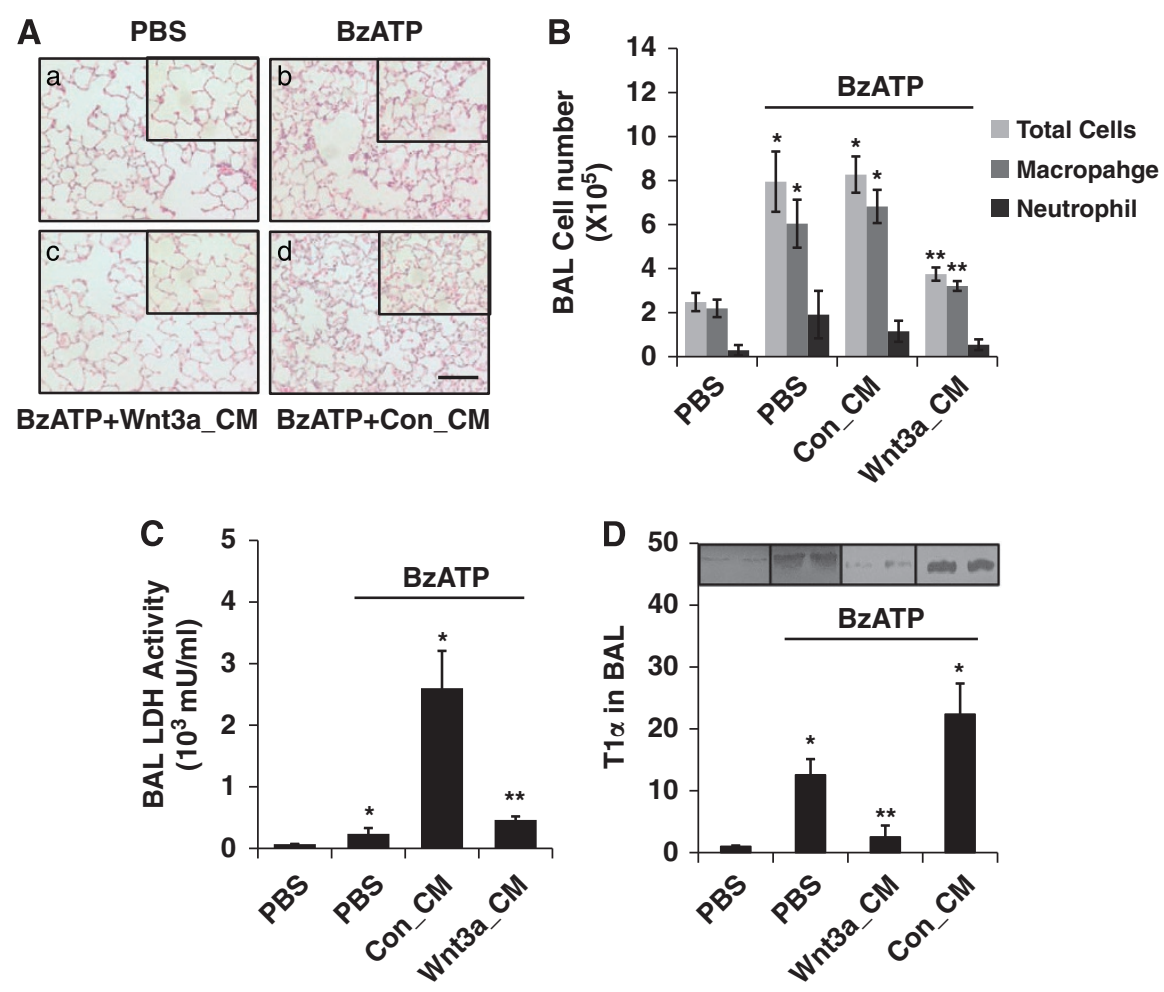

Figure 6 Wnt3a reduces AEC I death in BzATP-treated rat. The rats were intratracheally instilled with BzATP with control (Con) or Wnt3a CM for $24 \mathrm{~h}$. (A) Histological analysis. Paraffin sections $(4 \mu \mathrm{m})$ of the lungs were stained with H\&E. Control (a), BzATP (b), BzATP + Wnt3a_CM (c), and BzATP + Con_CM (d). Scale bar: $100 \mu \mathrm{m}$. (B) Total cell number and differential cell count in BAL. (C) LDH activity in BAL. (D) T1 $\alpha$ protein in BAL. Representative bands of western blots were shown. Values represent means \pm S.E.M. ( $n=8$ per group). Statistical significance was determined by one-way ANOVA analysis with post hoc Tukey's test. ${ }^{*} P<0.01$ versus PBS alone group. ${ }^{\star \star} P<0.01$ versus BzATP + Con_CM group
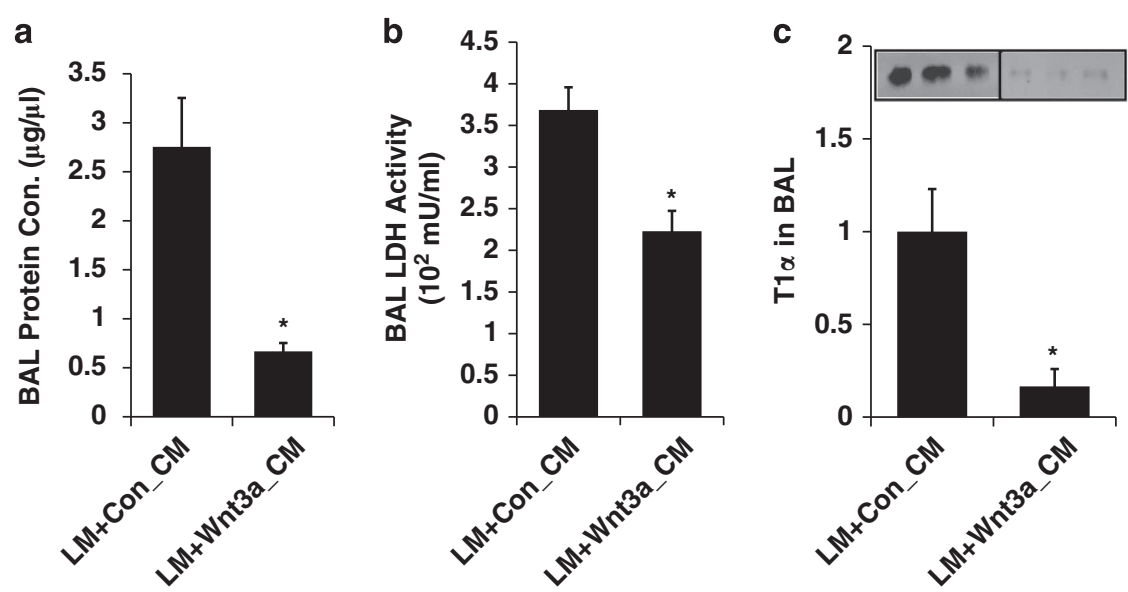

Figure 7 Wnt3a reduces AEC I death in LPS and mechanical ventilation (LM)-induced ALI in mice. The mice were intratracheally instilled with LPS (0.5 mg/kg) for $1 \mathrm{~h}$ and then ventilated for $2.5 \mathrm{~h}\left(12 \mathrm{ml} / \mathrm{kg}\right.$, a respiratory rate of 125 b.p.m. and $3 \mathrm{~cm} \mathrm{H}_{2} \mathrm{O}$ PEEP). (a) Protein concentration in BAL. (b) LDH activity in BAL. (c) T1 $\alpha$ protein in BAL. Values represent means \pm S.E.M. $\left(n=8\right.$ /group). Statistical significance was determined by Student's $t$-test. ${ }^{*} P<0.01$ versus $L M+C$ Con_CM group

activate $\mathrm{Wnt} / \beta$-catenin signaling in mice. These inhibitors attenuate the acute inflammation in blemocycin- and carrageenan-induced ALI. ${ }^{30}$ However, they also interfere with other signaling including $\mathrm{NF}_{\kappa} \mathrm{B}$ and NFAT. Our current findings provide proof-of-concept to manipulate $\mathrm{Wnt} / \beta$-catenin signaling as an efficient way to limit AEC I death during ALI.
Taken together, we demonstrate that P2X7R induces AEC I death by suppressing $\mathrm{Wnt} / \beta$-catenin signaling via activating GSK-3 $\beta$ and proteasome. Wnt3a overcomes P2X7R-mediated downregulation of $\mathrm{Wnt} / \beta$-catenin signaling and prevents AEC I death during the acute phase of ALI/ARDS (Figure 8). Our study on Wnt/ $\beta$-catenin signaling 


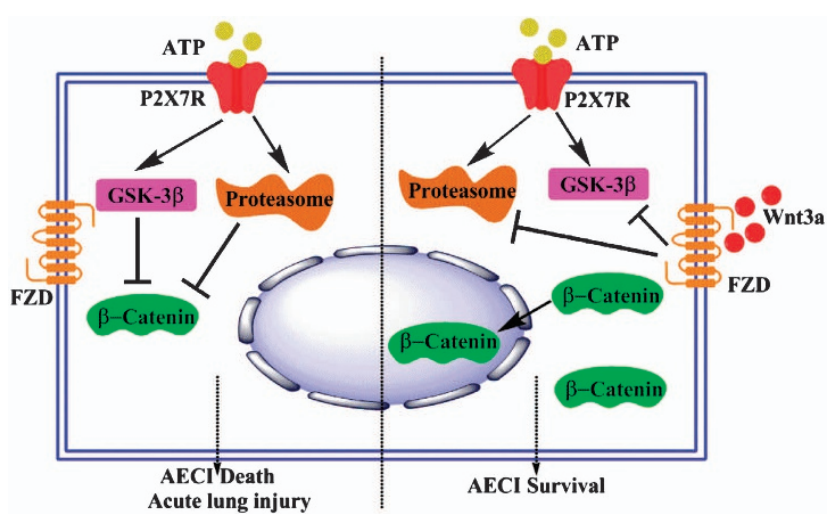

Figure 8 A model of P2X7R-induced AEC I death and Wnt3a-mediated protection. Activation of P2X7R by ATP activates GSK-3 $\beta$ and proteasome and leads to the degradation of $\beta$-catenin. This causes AEC I cell death. With the addition of Wnt3a, the activity of GSK-3 $\beta$ is inhibited. $\beta$-catenin is accumulated in the cytoplasmic and translocated into the cell nucleus, which enhances AEC I cell survival

and P2X7R-mediated purinergic signaling provides insights for future drug development and new therapeutic strategies of exploration.

\section{Materials and Methods}

Cell culture. E10 cells, a gift from Dr. Mary Williams (Pulmonary Center, Boston University School of Medicine, MA, USA), were cultured in CMRL 1066 supplemented with glutamax, penicillin/streptomycin, and 10\% heat-inactivated fetal bovine serum (FBS; Atlantic Biological, Miami, FL, USA). R3/1, a gift from Dr. Roland Koslowski, Technische Universität Dresden, Germany, was maintained in RPMI 1640 complemented with 10\% FBS and penicillin/streptomycin. HEK 293 cells (ATCC, Manassas, VA, USA) and HEK293 cells stably expressing rat P2X7R (HEK293-P2X7R), a gift from Dr. Annmarie Surprenant (University of Manchester, Manchester, UK) were maintained in DMEM supplemented with 10\% FBS and $100 \mu \mathrm{M}$ non-essential amino acids. A549 cells (ATCC) were cultured in RPMI 1640 medium containing 10\% FBS. H441 cells (ATCC) were maintained in F-12K medium complemented with $10 \%$ FBS. Cells were grown at $37^{\circ} \mathrm{C}$ in a humidified atmosphere containing $5 \% \mathrm{CO}_{2}$.

Primary AEC-I-like cells. Primary AEC--like cells were obtained by culturing primary AEC II on plastic plates for 7 days. To isolate AEC II, rat lung was perfused using solution II $(0.9 \% \mathrm{NaCl}, 0.1 \%$ glucose, $30 \mathrm{mM} \mathrm{HEPES}, 6 \mathrm{mM} \mathrm{KCl}, 0.1 \mathrm{mg} / \mathrm{ml}$ streptomycin sulfate, $0.07 \mathrm{mg} / \mathrm{ml}$ penicillin $\mathrm{G}, 0.07 \mathrm{mg} / \mathrm{ml}$ EGTA, $3 \mathrm{mM} \mathrm{Na}_{2} \mathrm{HPO}_{4}$, and $3 \mathrm{mM} \mathrm{NaH}_{2} \mathrm{PO}_{4}, \mathrm{pH}$ 7.4) to clear the red blood cells. Then the lung was lavaged with solution I (solution II plus $3 \mathrm{mM} \mathrm{MgSO}_{4}$ and $1.5 \mathrm{mM} \mathrm{CaCl}_{2}$ ) and digested with elastase ( 3 units/ml) for $3 \times 12 \mathrm{~min}$ at $37^{\circ} \mathrm{C}$. Then, the lung was chopped with a Mcllwain tissue chopper, and the cell suspension was digested with $100 \mathrm{ng} / \mathrm{ml}$ DNase I and filtered through 160- and 37- $\mu \mathrm{m}$ nylon mesh once and 15- $\mu \mathrm{m}$ nylon mesh twice. Then cells were seeded on rat IgG-coated polystyrene bacteriological plates twice for 45 and $30 \mathrm{~min}$ to remove macrophages. The unattached cells were collected using centrifugation. The isolated AEC II had a purity of $90 \%$ and a viability of over $98 \%$. To obtain AEC--like cells, AEC II were seeded onto 96-well tissue culture plastic dishes at a density of $1 \times 10^{6}$ cells/plate in MEM with $10 \% \mathrm{FBS}$. After overnight culture, the culture media were changed to DMEM supplemented with $10 \%$ FBS. The medium was changed every $48 \mathrm{~h}$ until day 7 .

Preparation of CM. Overexpressing soluble murine Wnt3a/Wnt5a cell lines and control murine L-cell line (ATCC) were maintained in DMEM supplemented with $10 \% \mathrm{FBS}, 1 \%$ L-glutamine, and $0.4 \mathrm{mg} / \mathrm{ml} \mathrm{G} 418$ (Invitrogen, Carlsbad, CA, USA). To obtain Wnt3a-, Wnt5a-, or control (Con)-CM, cells were cultured in fresh growth medium without G418 for 4 days and changed into fresh G418-free medium for additional 3 days. The cultured media were mixed, sterile-filtered, and stored at $-80^{\circ} \mathrm{C}$ until use. The activity of Wnt3a_CM was determined by a TOPflash assay performed in 293T cells. Wnt3a_CM normally showed an approximately sevenfold increase in the reporter activity compared with Con_CM.
To concentrate the soluble Wnt3a, $20 \mathrm{ml} \mathrm{Wnt3a} \mathrm{CM}$ was reduced into $2 \mathrm{ml} 10 \times$ Wnt3a_CM using an ultrafiltration kit (Millipore, Billerica, MA, USA).

Knockdown of P2X7R in E10 cells. Two adenovirus-based shRNA vectors, si-P2X7R ${ }^{1}$ and si-P2X7R, ${ }^{2}$ previously constructed in our laboratory were utilized to knockdown P2X7R. ${ }^{17}$ E10 cells were infected with virus control (si-control), si-P2X7R, ${ }^{1}$ and si-P2X7R ${ }^{2}$ for 4 days at a multiplicity of infection of 100 before BzATP treatment.

Cell viability and LDH assays. At the end of BzATP (Sigma-Aldrich, St. Louis, MO, USA) treatment, cell viability was assessed using the Cell Viability Assay Kit (Millipore), which measured the activities of mitochondrial dehydrogenases. Data were normalized to the control without any treatment. The release of LDH was measured with a LDH assay kit (Diagnostic Chemicals Inc., Oxford, CT, USA). The values were expressed as a percentage of actual LDH in the medium to the maximal LDH released by freeze-thaw insults.

Western blot. The cells were lysed in M-PER Mammalian Protein Extraction Reagent containing 1\% Halt Protease Inhibitor Cocktail (Pierce, Rockford, IL, USA) at $4{ }^{\circ} \mathrm{C}$, followed by sonication and freeze-thaw cycles. The proteins were separated in 10\% SDS-PAGE and transferred to nitrocellulose membranes. The membranes were stained with Ponceau-S to view the transfer quality. Then the membranes were blocked for $1 \mathrm{~h}$ at room temperature with $5 \%$ dried milk in Tris-buffered saline $(10 \mathrm{~mm}$ Tris $/ \mathrm{HCl}, 100 \mathrm{~mm} \mathrm{NaCl}$, and $0.05 \%$ Tween; $\mathrm{pH} 7.5$; TBS-T) and incubated overnight at $4{ }^{\circ} \mathrm{C}$ with anti-P2X7R (1:500, Sigma-Aldrich), anti-activated $\beta$-catenin (1:1000, Millipore), anti-total $\beta$-catenin $(1: 2000, \mathrm{BD}$ Transduction Laboratories, San Jose, CA, USA), anti-Bcl-2 (1:1000, Santa Cruz Biotechnology, Santa Cruz, CA, USA), anti-PCNA $(1: 2000$, Santa Cruz Biotechnology), anti-GSK-3 $\beta$ (1:2000, BD Transduction Laboratories), antiGSK-3 $\beta$ (pY216) (1:1000, BD Transduction Laboratories), anti-GSK-3 $\beta$ (pS9) (1:1000, Cell Signaling Technology, Danvers, MA, USA), anti- $\beta$-actin $(1: 2000$, Sigma), and anti-GAPDH (1:400, Santa Cruz Biotechnology) antibodies. The blots were then rinsed in TBS-T and incubated for $1 \mathrm{~h}$ at room temperature with goat anti-rabbit, or goat anti-mouse secondary antibodies, coupled to horseradish peroxidase $(1: 2000$, Jackson Immunoresearch, West Grove, PA, USA). After being washed, the blots were developed using SuperSignal West Pico Chemiluminescent Substrate (Pierce).

Quantitative real-time PCR. Total RNA was extracted from cells or tissues using TRI-Reagent (Molecular Research Center, Cincinnati, $\mathrm{OH}, \mathrm{USA}$ ) following the manufacturer's instructions. RNA was digested with TURBO DNase (Ambion, Austin, TX, USA) to remove the genomic DNA contamination. One microgram of RNA was reverse-transcribed into CDNA using M-MLV reverse transcriptase (Invitrogen), random primers, and oligo dT (Promega, Madison, WI, USA). Realtime PCR was carried out on 7900HT Fast Real-Time PCR System using SYBR Green I detection Master Mix (Eurogentec, San Diego, CA, USA). The primers were designed using the Primer Express software (Applied Biosystems, Foster City, CA, USA) and listed in Supplementary Table 1. PCR involved an initial denaturation step at $94^{\circ} \mathrm{C}$ for $5 \mathrm{~min}$, followed by 40 cycles of amplification $\left(94^{\circ} \mathrm{C}\right.$ for $30 \mathrm{~s}, 60^{\circ} \mathrm{C}$ for $1 \mathrm{~min}$ ). A dissociation curve was generated after each PCR to view the specificity of the amplification. All of the data were normalized to $18 \mathrm{~S}$ rRNA.

Immunofluorescence. E10 cells were cultured on 24-well plastic plates. Before collection, the cells were briefly washed with PBS and fixed with $4 \%$ paraformaldehyde for $15 \mathrm{~min}$. After being washed with PBS, the cells were permeabilized with $0.3 \%$ Triton X-100 for 10 min and blocked with $10 \%$ FBS for $1 \mathrm{~h}$ at room temperature. After rinsing, the cells were incubated overnight with primary antibodies against $\beta$-catenin $(1: 200)$. Subsequently, cells were washed with PBS and incubated with Alexa 568-conjugated goat anti-mouse IgG (Invitrogen) for $1 \mathrm{~h}$. Images were acquired using a Nikon Eclipse TE-2000 inverted fluorescence microscope (Nikon Instruments, Melville, NY, USA).

TOPflash assay. E10 cells were seeded in 96-well plastic plates. After reaching $85 \%$ confluence, the cells were transfected with $1 \mathrm{ng}$ Renilla luciferase control plasmid phRL-TK (Promega) and $20 \mathrm{ng}$ LEF/TCF reporter plasmid TOPflash (Millipore) or FOPflash (a negative control plasmid for TOPflash, which has mutated LEF/TCF-binding sites) using Lipofectamine 2000 (Invitrogen). After $24 \mathrm{~h}$, cells were treated with $400 \mu \mathrm{M}$ BzATP for $0-12 \mathrm{~h}$. Dual-luciferase assay was performed using the Dual-Luciferase Reporter Assay System (Promega). 
Proteasome activity assay. To measure proteasome activity, $100 \mu \mathrm{g}$ of cell lysate was diluted with assay buffer ( $50 \mathrm{mM}$ Tris (pH 7.4), $5 \mathrm{mM} \mathrm{MgCl}_{2}, 2 \mathrm{mM}$ dithiothreitol, and $2 \mathrm{mM} \mathrm{ATP}$ ) to a final volume of $1 \mathrm{ml}$ and incubated with $50 \mu \mathrm{M}$ fluorogenic proteasome substrate Suc-LLVY-AMC (AnaSpec, Fremont, CA, USA). Proteolytic activities, reflected by the release of the fluorescent group, 7-amido-4methylcoumarin (AMC), were continuously monitored in $30 \mathrm{~min}$ at $37^{\circ} \mathrm{C}$ by a fluorescence plate reader (Spectramax M2, Molecular Devices, Sunnyvale, CA, USA) with excitation and emission wavelengths of 380 and $460 \mathrm{~nm}$, respectively.

Animals. Male C57BL/6N mice (6-8 weeks old) were purchased from Jackson Laboratory (Bar Harbor, ME, USA). Male Sprague-Dawley rats were purchased from Charles River Breeding Laboratories (Wilmington, MA, USA). All the animals were housed and cared for by the Laboratory Animal Resource Unit, Oklahoma State University. Experimental protocols were reviewed and approved by the Institutional Animal Care and Use Committee of Oklahoma State University.

BzATP-induced ALI in rat. Male Sprague-Dawley rats $(275-300 \mathrm{~g})$ were divided into four groups ( $n=8 /$ group): (1) vehicle (200 $\mu \mathrm{l} \mathrm{PBS),} \mathrm{(2)} \mathrm{BzATP} \mathrm{(10} \mathrm{mg/kg}$ b.w. BzATP in $200 \mu \mathrm{l}$ PBS), (3) BzATP and Wnt3a_CM (10 mg/kg b.w. BzATP in $100 \mu \mathrm{l}$ PBS, and $100 \mu \mathrm{l}$ 10X Wnt3a_CM), and (4) BzATP and Con_CM (10 mg/kg b.w. BzATP in $100 \mu \mathrm{l}$ PBS, and $100 \mu \mathrm{l}$ 10X Con_CM). Rats were anesthetized with intraperitoneal injection of ketamine $(40 \mathrm{mg} / \mathrm{kg} \mathrm{b.w.)}$ and xylazine $(8 \mathrm{mg} / \mathrm{kg} \mathrm{b.w.)}$. All of the reagents were intratracheally instilled. Twenty-four hours after intratracheal instillation, a tracheotomy was performed. Bronchoalveolar lavage (BAL) was collected by lavaging the right lungs with $10 \mathrm{ml}$ of normal saline. After centrifugation at $380 \times \mathrm{g}$ for $10 \mathrm{~min}$ at $4^{\circ} \mathrm{C}$, the cell pellets were resuspended in $1 \mathrm{ml}$ of normal saline. Cell-free BAL and tissue samples of lavaged right lungs were immediately frozen in liquid nitrogen and stored at $-80^{\circ} \mathrm{C}$ for subsequent analysis. Unlavaged left lungs were fixed in $4 \%$ paraformaldehyde for histological analysis.

LPS-induced ALI in a ventilated mouse model. Male C57BL/6N mice (8 weeks) were divided into four groups ( $n=8 /$ group): (1) LPSs from Escherichia coli 055:B5 (0.5 mg/kg b.w.) in $20 \mu \mathrm{l} 10 \mathrm{X}$ Wnt3a CM, (2) LPS $0.5 \mathrm{mg} / \mathrm{kg} \mathrm{b.w.} \mathrm{in}$ $20 \mu \mathrm{l}$ 10X Con_CM, (3) LPS $0.5 \mathrm{mg} / \mathrm{kg}$ b.w. in $20 \mu \mathrm{l}$ normal saline, and (4) Control, without LPS and MV. LPS was intratracheally delivered into the lung. One hour after intratracheal instillation, mice were ventilated with a tidal volume of $12 \mathrm{ml} / \mathrm{kg}$, a rate of 125 b.p.m., and $3 \mathrm{~cm} \mathrm{H} \mathrm{H}_{2} \mathrm{O}$ PEEP for $2.5 \mathrm{~h}$. At the end of ventilation, a tracheotomy was performed. The lungs were lavaged with $1 \mathrm{ml}$ of normal saline three times. BAL was collected and centrifuged at $380 \times g$ for 10 min at $4{ }^{\circ} \mathrm{C}$. BAL cell pellets were resuspended in $200 \mu \mathrm{l}$ of normal saline for subsequent analysis. Cell-free BAL fluid and lavaged lung tissue samples were frozen in liquid nitrogen and stored in $-80^{\circ} \mathrm{C}$ freezer.

BAL analysis. Protein concentrations in the BAL fluid were determined using a Bio-Rad protein assay (Bio-Rad Laboratories, Hercules, CA, USA). The total number of cells in BAL was counted with a hemocytometer. Differential cell count was performed on the BAL cells visualized with Wright-Giemsa staining. LDH activity in the BAL fluid was determined using a Cytotoxicity Detection kit (Roche Applied Sciences, Indianapolis, IN, USA) using type III L-lactic dehydrogenase (Sigma-Aldrich) as standards.

Western blot for T1 $\alpha$ in BAL. For rat samples, BAL fluid $(70 \mu$ l) was added with $7 \mu \mathrm{l}$ SDS sample buffer $(62.5 \mathrm{mM}$ Tris $\mathrm{HCl}, \mathrm{pH} 6.8$, containing $5 \%$ 2-mercaptoethanol, $2 \%$ SDS, $10 \%$ glycerol, and $0.01 \%$ bromophenol blue) and heated at $95^{\circ} \mathrm{C}$ until $25 \mu$ l volume was reached. A monoclonal anti-T1 $\alpha(1: 2000$, a gift from Dr. Mary C Williams, Boston University) antibody was used as a primary antibody. For mouse samples, BAL fluid $(20 \mu \mathrm{l})$ was added with $4 \mu \mathrm{l}$ SDS sample buffer and heated at $95^{\circ} \mathrm{C}$ for $10 \mathrm{~min}$. A hamster anti-T1 $\alpha(1: 2000,8.1 .1$, DHSB, lowa City, IO, USA) was used as a primary antibody. Films were developed and scanned. The densities of bands were quantified using the ImageJ software (National Institutes of Health, Bethesda, MD, USA (http://rsb.info.nih.gov/ij/)).

Statistical analysis. The results were analyzed using one-way ANOVA with post hoc Tukey's test for multiple comparisons of control and treatment groups, or Student's t-test using GraphPad Prism (version 6). All results were reported as means \pm S.E.M. ( $n=3-8$ for each condition).

\section{Conflict of Interest}

The authors declare no conflict of interest.
Acknowledgements. We thank Dr. Mary Williams (Boston University) for providing anti-T1 $\alpha$ antibody and E10 cells with the permission of Dr. Al Malkinson (University of Colorado), Dr. Annmarie Surprenant (University of Manchester) for HEK293-P2X7R cells, Dr. Roland Koslowski (Dresden University of Technology) for R3/1 cells, Dr. Joseph Alcorn (University of Texas Health Sciences Center at Houston) for MLE15 cells, Dr. Rama Mallamaplli (University of Pittsburgh) for PreTIl cells. Hamster anti-mouse T1 $\alpha$ antibody developed by Dr. Andrew Farr (University of Washington) was obtained from the Developmental Studies Hybridoma Bank developed under the auspices of the NICHD and maintained by The University of lowa, Department of Biology, lowa City, IA 52242, USA. This work was supported by the National Heart, Lung and Blood Institute under Award Numbers R01HL083188, 071628, and 052146 (to LL) and the National Institute of General Medical Sciences under award number P20GM103648 (Molecular Biology Core facility). The content is solely the responsibility of the authors and does not necessarily represent the official views of the National Institutes of Health. YG was supported by predoctoral fellowships (no. 09PRE2300211) from the American Heart Association.

1. Matthay MA, Zemans RL. The acute respiratory distress syndrome: pathogenesis and treatment. Annu Rev Pathol 2011; 6: 147-163.

2. Dobbs LG, Johnson MD, Vanderbilt J, Allen L, Gonzalez R. The great big alveolar TI cell: evolving concepts and paradigms. Cell Physiol Biochem 2010; 25: 55-62.

3. Chen J, Chen Z, Chintagari NR, Bhaskaran M, Jin N, Narasaraju T et al. Alveolar type I cells protect rat lung epithelium from oxidative injury. J Physiol 2006; 572: 625-638.

4. Tang PS, Mura M, Seth R, Liu M. Acute lung injury and cell death: how many ways can cells die? Am J Physiol Lung Cell Mol Physiol 2008; 294: L632-L641.

5. Clevers H, Nusse R. Wnt/beta-catenin signaling and disease. Cell 2012; 149: 1192-1205.

6. Weng T, Gao L, Bhaskaran M, Guo Y, Gou D, Narayanaperumal J et al. Pleiotrophin regulates lung epithelial cell proliferation and differentiation during fetal lung development via beta-catenin and Dlk1. J Biol Chem 2009; 284: 28021-28032.

7. Wang $Y$, Huang $C$, Reddy CN, Bhaskaran M, Weng T, Guo Y et al. miR-375 regulates rat alveolar epithelial cell trans-differentiation by inhibiting Wnt/beta-catenin pathway. Nucleic Acids Res 2013; 41: 3833-3844.

8. Tanjore H, Degryse AL, Crossno PF, Xu XC, McConaha ME, Jones BR et al. beta-catenin in the alveolar epithelium protects from lung fibrosis after intratracheal bleomycin. Am J Respir Crit Care Med 2013; 187: 630-639.

9. Konigshoff M, Kramer M, Balsara N, Wilhelm J, Amarie OV, Jahn A et al. WNT1-inducible signaling protein-1 mediates pulmonary fibrosis in mice and is upregulated in humans with idiopathic pulmonary fibrosis. J Clin Invest 2009; 119: 772-787.

10. Sharma S, Tantisira K, Carey V, Murphy AJ, Lasky-Su J, Celedon JC et al. A role for WNT-signaling genes in the pathogenesis of impaired lung function in asthma. Am J Respir Crit Care Med 2009; 181: 328-336.

11. Kneidinger N, Yildirim AO, Callegari J, Takenaka S, Stein MM, Dumitrascu R et al. Activation of the WNT/beta-catenin pathway attenuates experimental emphysema. Am J Respir Crit Care Med 2011; 183: 723-733.

12. Wang R, Ahmed J, Wang G, Hassan I, Strulovici-Barel Y, Hackett NR et al. Down-regulation of the canonical Wnt beta-catenin pathway in the airway epithelium of healthy smokers and smokers with COPD. PLoS One 2011; 6: e14793.

13. Flozak AS, Lam AP, Russell S, Jain M, Peled ON, Sheppard KA et al. \{beta\}-catenin/TCF signaling is activated during lung injury and promotes the survival and migration of alveolar epithelial cells. J Biol Chem 2009; 285: 3157-3167.

14. Zemans RL, Briones N, Campbell M, McClendon J, Young SK, Suzuki T et al. Neutrophil transmigration triggers repair of the lung epithelium via beta-catenin signaling. Proc Natl Acad Sci USA 2011; 108: 15990-15995.

15. Khakh BS, North RA. P2X receptors as cell-surface ATP sensors in health and disease. Nature 2006; 442: 527-532.

16. Chen Z, Jin N, Narasaraju T, Chen J, McFarland LR, Scott M et al. Identification of two novel markers for alveolar epithelial type I and II cells. Biochem Biophys Res Commun 2004; 319: 774-780.

17. Mishra A, Chintagari NR, Guo Y, Weng T, Su L, Liu L. Purinergic P2X7 receptor regulates lung surfactant secretion in a paracrine manner. J Cell Sci 2011; 124(Pt 4): $657-668$.

18. Hanley PJ, Kronlage M, Kirschning $\mathrm{C}$, del RA, Di VF, Leipziger $\mathrm{J}$ et al. Transient P2X7 receptor activation triggers macrophage death independent of Toll-like receptors 2 and 4, caspase-1, and pannexin-1 proteins. J Biol Chem 2012; 287: 10650-10663.

19. Jun DJ, Kim J, Jung SY, Song R, Noh JH, Park YS et al. Extracellular ATP mediates necrotic cell swelling in SN4741 dopaminergic neurons through P2X7 receptors. J Biol Chem 2007; 282: 37350-37358.

20. Moncao-Ribeiro LC, Cagido VR, Lima-Murad G, Santana PT, Riva DR, Borojevic R et al. Lipopolysaccharide-induced lung injury: role of P2X7 receptor. Respir Physiol Neurobiol 2011; 179: 314-325.

21. Ferrari D, Pizzirani C, Adinolfi E, Lemoli RM, Curti A, Idzko M et al. The P2X7 receptor: a key player in IL-1 processing and release. J Immunol 2006; 176: 3877-3883. 
22. Altemeier WA, Matute-Bello G, Frevert CW, Kawata Y, Kajikawa O, Martin TR et al. Mechanical ventilation with moderate tidal volumes synergistically increases lung cytokine response to systemic endotoxin. Am J Physiol Lung Cell Mol Physiol 2004; 287: L533-L542.

23. Doubravska L, Simova S, Cermak L, Valenta T, Korinek V, Andera L. Wnt-expressing rat embryonic fibroblasts suppress Apo2L/TRAIL-induced apoptosis of human leukemia cells. Apoptosis 2008; 13: 573-587.

24. You L, He B, Xu Z, Uematsu K, Mazieres J, Fujii N et al. An anti-Wnt-2 monoclonal antibody induces apoptosis in malignant melanoma cells and inhibits tumor growth. Cancer Res 2004; 64: 5385-5389.

25. Riteau N, Gasse P, Fauconnier L, Gombault A, Couegnat M, Fick L et al. Extracellular ATP is a danger signal activating $\mathrm{P} 2 \mathrm{X} 7$ receptor in lung inflammation and fibrosis. Am J Respir Crit Care Med 2010; 182: 774-783.

26. Gulbransen BD, Bashashati M, Hirota SA, Gui X, Roberts JA, MacDonald JA et al Activation of neuronal $\mathrm{P} 2 \mathrm{X} 7$ receptor-pannexin-1 mediates death of enteric neurons during colitis. Nat Med 2012; 18: 600-604.

27. Wang X, Arcuino G, Takano T, Lin J, Peng WG, Wan $P$ et al. P2X7 receptor inhibition improves recovery after spinal cord injury. Nat Med 2004; 10: 821-827.

28. Taylor SR, Turner CM, Elliott JI, McDaid J, Hewitt R, Smith J et al. P2X7 deficiency attenuates renal injury in experimental glomerulonephritis. J Am Soc Nephrol 2009; 20: 1275-1281.
29. Lucattelli M, Cicko S, Muller T, Lommatzsch M, de CG, Cardini S et al. P2X7 receptor signalling in the pathogenesis of smoke-induced lung inflammation and emphysema. Am J Respir Cell Mol Biol 2011; 44: 423-429.

30. Cuzzocrea S, Crisafulli C, Mazzon E, Esposito E, Muia C, Abdelrahman M et al. Inhibition of glycogen synthase kinase-3beta attenuates the development of carrageenan-induced lung injury in mice. Br J Pharmacol 2006; 149: 687-702.

cc)(-) Cell Death and Disease is an open-access journal published by Nature Publishing Group. This work is licensed under a Creative Commons Attribution-NonCommercialShareAlike 3.0 Unported License. The images or other third party material in this article are included in the article's Creative Commons license, unless indicated otherwise in the credit line; if the material is not included under the Creative Commons license, users will need to obtain permission from the license holder to reproduce the material. To view a copy of this license, visit http://creativecommons.org/ licenses/by-nc-sa/3.0/

Supplementary Information accompanies this paper on Cell Death and Disease website (http://www.nature.com/cddis) 